\title{
Review
}

\section{Imaging of the spleen in malaria}

\section{Mireia Ferrer ${ }^{\mathrm{a}, 1}$, Lorena Martin-Jaular ${ }^{\mathrm{a}}$, Mariana De Niz ${ }^{\mathrm{a}, \mathrm{b}}$, Shahid M. Khan ${ }^{\mathrm{c}}$, Chris J. Janse ${ }^{\mathrm{c}}$, Maria Calvo ${ }^{\mathrm{d}}$, Volker Heussler ${ }^{\mathrm{b}}$, Hernando A. del Portillo ${ }^{\mathrm{a}, \mathrm{e}, *}$}

a Barcelona Centre for International Health Research (CRESIB, Hospital Clínic-Universitat de Barcelona) ISGlobal, Barcelona, Spain

${ }^{\mathrm{b}}$ Institute of Cell Biology, University of Bern, Bern, Switzerland

c Leiden Malaria Research Group Parasitology, Center of Infectious Diseases, Leiden University Medical Center, Leiden, The Netherlands

d Advanced Light Microscopy Unit, School of Medicine, Scientific and Technological Centers, University of Barcelona, Spain

e Institució Catalana de Recerca i Estudis Avançats (ICREA), Barcelona, Spain

\section{A R T I C L E I N F O}

Available online $\mathrm{xxxx}$

\begin{abstract}
A B S T R A C T
Splenomegaly, albeit variably, is a hallmark of malaria; yet, the role of the spleen in Plasmodium infections remains vastly unknown. The implementation of imaging to study the spleen is rapidly advancing our knowledge of this so-called "blackbox" of the abdominal cavity. Not only has ex vivo imaging revealed the complex functional compartmentalization of the organ and immune effector cells, but it has also allowed the observation of major structural remodeling during infections. In vivo imaging, on the other hand, has allowed quantitative measurements of the dynamic passage of the parasite at spatial and temporal resolution. Here, we review imaging techniques used for studying the malarious spleen, from optical microscopy to in vivo imaging, and discuss the bright perspectives of evolving technologies in our present understanding of the role of this organ in infections caused by Plasmodium.
\end{abstract}

(C) 2013 Published by Elsevier Ireland Ltd.

\section{Contents}

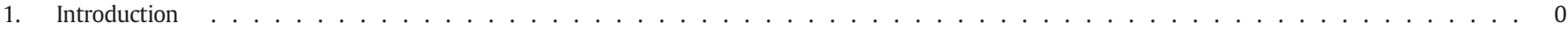

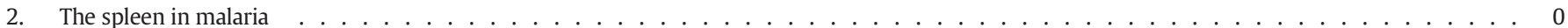

3. Conserved and differential features of human and murine

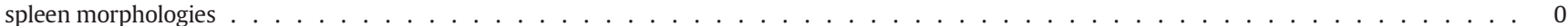

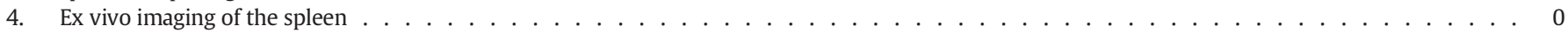

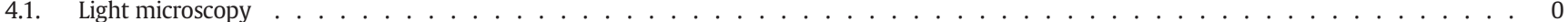

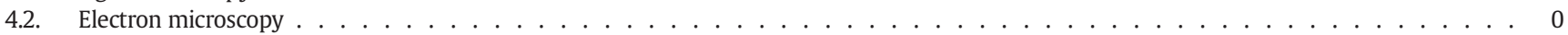

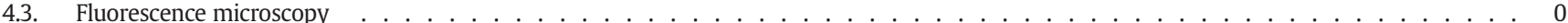

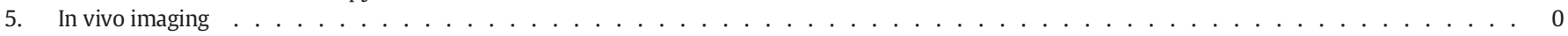

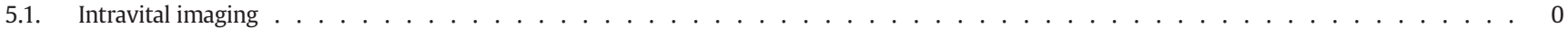

5.2. Quantitative imaging of parasite-spleen interactions . . . . . . . . . . . . . . . . . . . . . . . . . . . . . . . 0

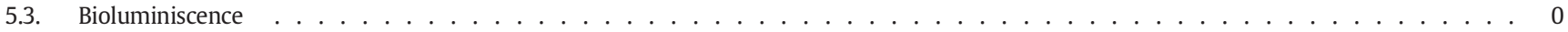

5.4. Magnetic resonance imaging . . . . . . . . . . . . . . . . . . . . . . . . . . . . . 0

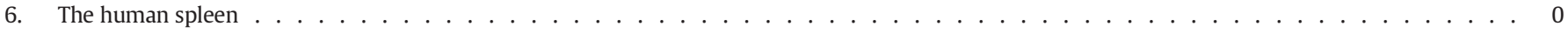

6.1. Computed tomography: findings in human malarial spleen . . . . . . . . . . . . . . . . . . . . . . . . . . . . 0

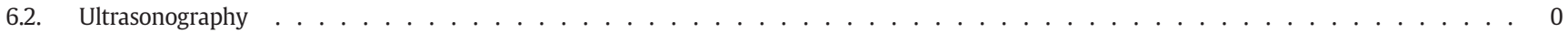

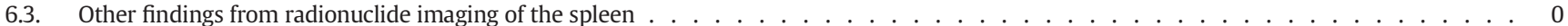

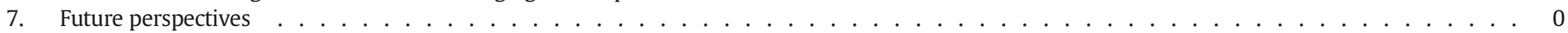

7.1. Novel imaging technologies . . . . . . . . . . . . . . . . . . . . . . . . . . . . . 0

7.2. 3D model of the human spleen $\ldots \ldots \ldots \ldots \ldots$

\footnotetext{
* Corresponding author at: Barcelona Centre for International Health Research (CRESIB, Hospital Clínic-Universitat de Barcelona), Barcelona, Spain. Tel.: +34 690737229; fax: +34 933129410.

E-mail address: hernandoa.delportillo@cresib.cat (H.A. del Portillo).

1 Present address: Centre d'études d'agents Pathogènes et Biotechnologies pour la Santé, Montpellier, France.
} 


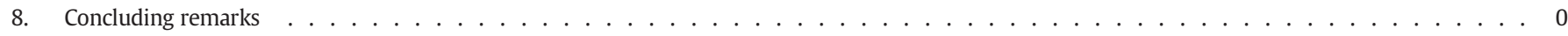

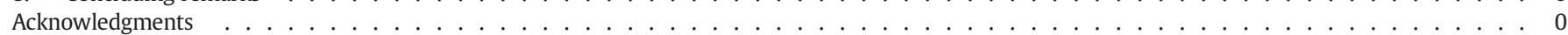

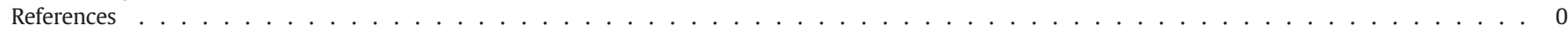

\section{Introduction}

The spleen is a secondary lymphoid organ perfectly adapted to induce innate and adaptive immune responses, and to phagocytose both senescent and damaged red blood cells (RBCs) and blood-borne pathogens including the malaria parasite, Plasmodium spp. [1,2]. The capacity to perform these functions is closely linked to the complex structure of the spleen formed by (i) the white pulp, a lymphoid area composed of $\mathrm{T}$ and B cell zones where acquired immune responses develop; (ii) the red pulp, an important area for blood-filtering and iron recycling; and (iii) the marginal zone, a transit area harboring a large number of cells with unique properties that enable the efficient surveillance of circulating blood (Fig. 1).

Due to ethical and technical constraints for its study, the spleen was for long considered an 'orphan' organ, or a so-called 'black box' in the abdominal cavity [1]. In the past, studies of spleen pathology were mostly limited to post-mortem examinations and to the observation of surgically removed spleens [3]. It was not until the early 1930s that the advent of ex vivo imaging of fixed splenic structures, and of spleen cell dynamics in vitro provided invaluable information about the ultrastructure of cells and tissues of this organ in healthy and pathological states $[4,5]$. In the last two decades, the emergence of advanced dynamic live imaging modalities has enhanced our understanding of immune cell function and cell-cell communication in healthy and diseased states, as well as promising developments in immunoimaging in situ in organs including the spleen [6,7].

\section{The spleen in malaria}

Infections by malaria parasites induce a dramatic, albeit variable splenic response mostly characterized by splenomegaly. In fact, spleen size has been used as a tool to determine the intensity of malaria transmission in endemic regions [8-10]. Of note, during the erythrocytic stages of malaria infection, the spleen is the main organ involved in the development of the immune response and in elimination of pRBCs $[2,11]$. However, parasites retaliate by establishing chronic infections through evasion and modulation of immune responses and by remodeling the spleen, sometimes leading to immunopathology and severe disease [12]. In addition, several Plasmodium species escape spleen clearance through cytoadherence to endothelial cells in inner organs causing end-organ dysfunction $[13,14]$. The dual role of the spleen in protection and pathology, for instance in cerebral malaria and severe malarial anemia, highlights the need for further research on this organ.

The relevance of the spleen for control of malaria infection comes from direct evaluation of splenectomized human patients and rodent models. Several cases of Plasmodium falciparum-infected patients with various states of immunological competence, suffering splenectomy, have been reported [15]. In immune individuals, for instance, the

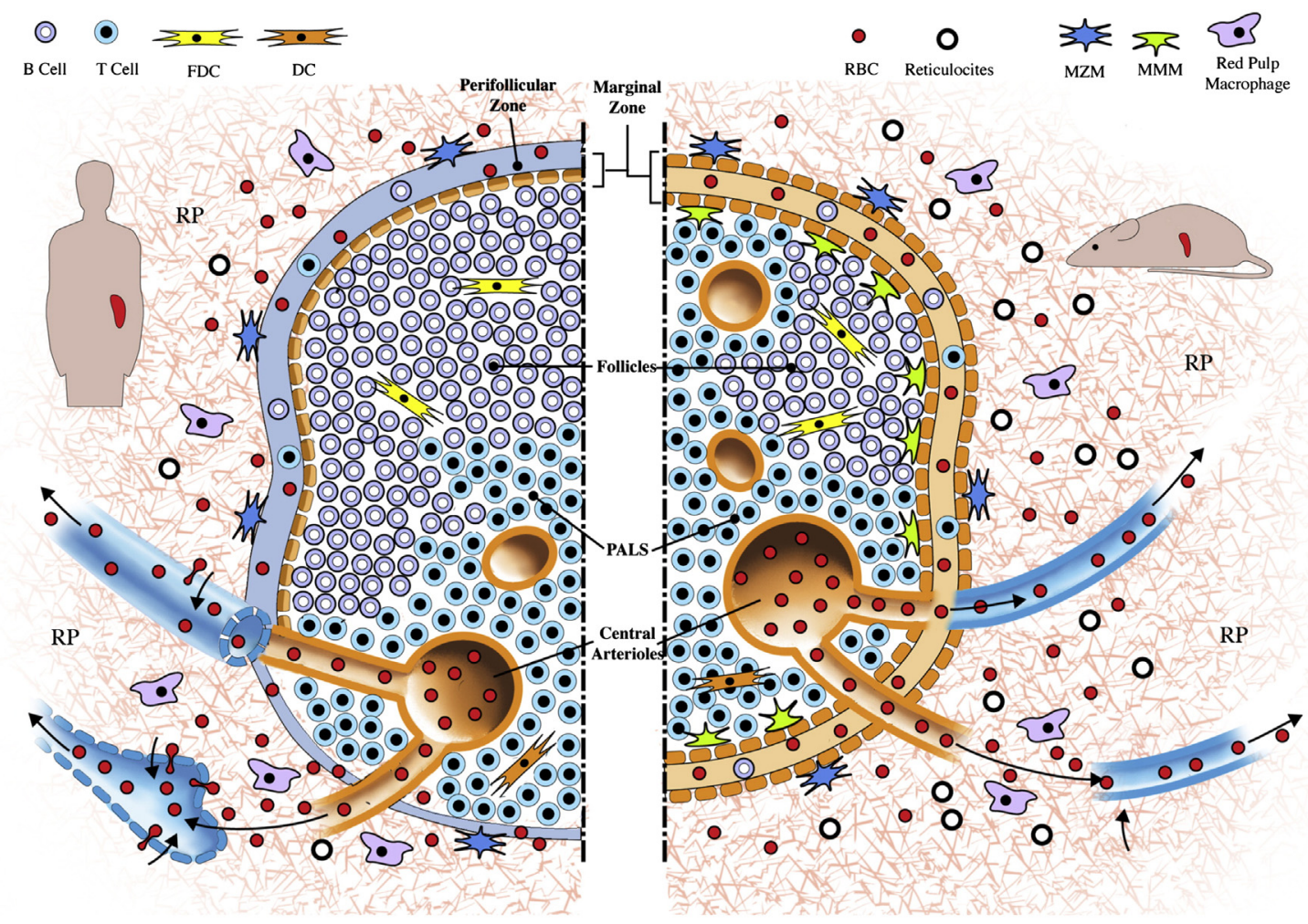

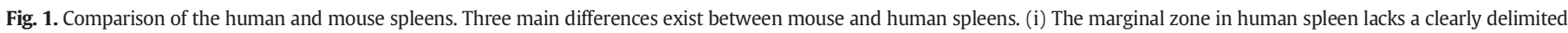

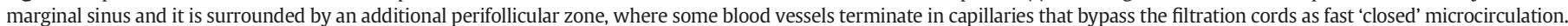

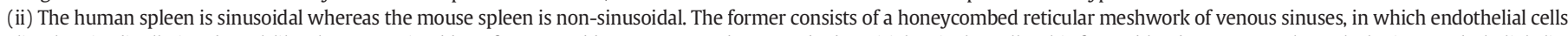

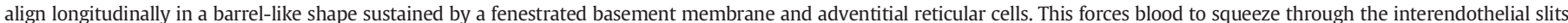

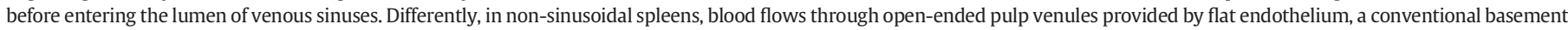

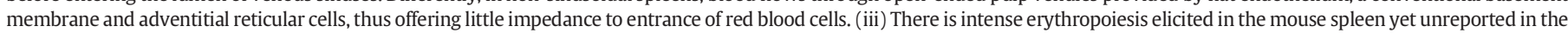
human spleen. FDC, follicular dendritic cell; MMM, marginal metallophilic macrophages; MZM, marginal zone macrophages. Figure originally published in [11]. 
absence of a spleen aggravated the course of the disease, while antibody mediated clearance of pRBCs was undertaken by other organs though less efficiently. The spleen has also been found to play a role in chronifying infection, since removal of the spleen in a chronic carrier led to a significant increase in peripheral parasite loads and acute attack [16]. In addition, clearance of pRBCs in splenectomized patients undergoing anti-malarial treatment showed a marked delay in comparison to patients with functional spleens. On the other hand, splenectomy of both $P$. falciparum and Plasmodium vivax non-immune patients $[17,18]$ has been related to aggravated severity and increased risk of death due to malaria. Overall, while the spleen may not be essential for parasite clearance in partially immune, splenectomized patients, it exerts a major protective role in non-immune patients, via macrophage responses or mechanical retention/filtering of parasites. In addition to pathological complications, higher numbers of parasitemia and of circulating mature forms were found in splenectomized patients. Similar to these observations in humans, in Plasmodium chabaudi- or Plasmodium yoelii-infected mice $[19,20]$, prolonged waves of parasitemias and impaired parasite clearance have also been linked to splenectomy. Of interest, $P$. yoelii $17 \mathrm{X}$ infection in mice from distinct backgrounds responded differently to splenectomy: DBA/2 mice were not adversely affected by removal of the spleen, while $\mathrm{C} 57 \mathrm{BL} / 6$ and $\mathrm{Balb} / \mathrm{c}$ mice failed to resolve infection. The lower parasitemia levels in splenectomized mice were attributed to the lack of spleen-derived reticulocytes for parasitation [19]. Thereafter, host genotype may influence splenic response to infection, in which alternative mechanisms, such as pRBC phagocytosis in the liver, as well as bone marrow hematopoiesis, may help to overcome the lack of spleen.

A second line of evidence for the importance of the spleen in malaria comes from architectural remodeling which is so extensive, that in the past it led to the hypothesis that the spleen structure had evolved as a response to the presence of the parasite [21]. In fact, the complex anatomy of the spleen brings together adaptive and innate immune responses, ensuring filtration and careful surveillance of pRBCs in specialized splenic compartments. In the red pulp, macrophages uptake circulating and opsonized pRBCs, and mechanical filtering occurs [22,23]. In the white pulp and marginal zone, parasite capture and antigen processing by specialized dendritic cells leads to antigen-specific T cell priming, DC modulation, and B cell modulation as well as their repositioning to deliver antibodies into the circulation $[2,8]$. Given this link between structure and function, compromise of splenic compartments leads to alterations in organ-specific and systemic immune responses in ways that are not yet fully understood.

\section{Conserved and differential features of human and murine spleen morphologies}

Imaging methods have enabled us not only to characterize the morphology, structure, and function of the spleen in health and disease states, but also to study comparative morphology of this organ in various animal species. This has been key for determining the validity of experimental animal models to study events in the spleen, including malaria infections. A certain uniqueness between the spleens of different animals, such as dogs, horses, cats, monkeys, rats, and mice, has been documented. Banks et al. first proposed the classification of spleens into 'storage', and 'defense' spleens, based on the morphology of capsular and trabecular smooth muscle fibers [24]. More recently, Dellman and Brown proposed the classification of mammalian spleens into sinusal and non-sinusal, based on the type of post-capillary vessels present in the organ [25]. Based on this latter classification, the human and rat spleens are sinusal, while the murine spleen has no arteriovenous shunts, and is non-sinusal; this is considered a key difference for our understanding of splenic function in malaria research. While spleen remodeling during malaria infections has been observed in all animals studied, whether specific structural differences between humans and experimental animals - for instance, mice - invalidate them as models to study malaria remains a matter of controversy (Table 1 ). Specific differences in splenic responses during malaria between humans, rodents, and monkeys has been reviewed elsewhere [11]. However, in this section we will focus on overall morphological differences between murine and human spleens imaged over the last few decades.

Although important anatomical differences between humans and rodents exist, multiple morphological features are conserved [26]. This fact, together with observations on malaria responses in animal models gives rise to the question on whether spleen-dependent mechanisms of immunity against malaria might in fact, be redundant. Nevertheless, various authors have commented on the need to observe care when extrapolating results from one species to another.

Balogh et al. recently reviewed in great detail the reported observations on differences existing between human and mice spleens, gathered through the use of a variety of immunohistochemistry, confocal, and advanced fluorescence microscopy techniques [26]. A key splenic component that shows significant differences between human and mice is the marginal zone (MZ). Human spleens possess a perifollicular zone lined by MAdCAM-1 + cells, and populated by specialized cell types; this structure is altogether absent in mice and rats. Nevertheless, mice possess a fibroblastic stromal microdomain reminiscent of the perifollicular zone in humans [27]. Reportedly, the presence or absence of the perifollicular zone and its components impacts on the vascular structure and branching of the arterioles in the different species, as well as possibly influencing the morphology of efferent lymphatic vessels in the white pulp. Whether these differences have an impact on leukocyte circulation patterns, as well as response to infection, remains undetermined [27]. For malaria research, this is of relevance, as the marginal zone has been shown to be a key compartment differentially remodeled by the Plasmodium parasite in lethal and non-lethal infections. While various significant differences between species have been reported with regard to the microarchitecture of the spleen, organogenesis, and anlage, these topics are outside the scope of the present review.

As previously stated, various features of the splenic morphology are conserved among species. Similarities between murine and human spleens include the scaffolding structure surrounding the lymphoid architecture of the organ, and its composition (namely, vasculature and fibroblastic meshwork); presence of a conduit system; the compartmentalization of the spleen into white pulp, red pulp, and marginal zone; the overall composition and structure of the white pulp; the composition of the terminal segments of arteriolar capillaries within the red pulp and their lining by ellipsoid sheaths; the presence of fibroblastic reticular cells, and the conserved role they play in enabling ordered lymphocyte migration. The differences with regard to the splenic red pulp remain poorly studied and incompletely understood.

More novel studies on spleen morphology using advanced fluorescence and electron microscopy techniques with potential relevance for the malaria field have been done in mice and humans. Among the most relevant observations in mouse spleens is the description of the conduit system in the white pulp, by Nolte et al. [28], which aside from playing a role in the separation of fluid extracellular spaces and parenchymal compartments, may also be implicated in the directional movement of lymphocytes via the display of specific chemokines. In humans, one of the most novel observations, done by Ogembo et al. [29], focused on unique markers of littoral cells, a potentially key, yet understudied population of the human splenic red pulp. This specialized, highly plastic cell population is thought to be unique to Hominidae [30]. The importance of littoral cells is believed to lie on their role as a determinant for cell recirculation following passage through the splenic red pulp. On one hand, it has been shown that prior to return to venous circulation, splenic constituents have an obligatory passage through the littoral cells, lining the venous sinuses. On the other hand, various blood components, including leukocytes, phagocytosed erythrocytes, hemosiderin, and debris, have been visualized within littoral cells. This has led to the suggestion that they may be key mediators of pathogen clearance and cellular filtration, although functional evidence remains 
Table 1

Main findings of the role of the spleen in human and experimental malaria infections.

\begin{tabular}{|c|c|c|}
\hline & Human & Animal models \\
\hline $\begin{array}{l}\text { Protective role } \\
\text { of the spleen in } \\
\text { malaria infection }\end{array}$ & $\begin{array}{l}\text {-Major protective role of the spleen in } P \text {. falciparum and } P \text {. vivax } \\
\text { non-immune patients }[18,107] \\
\text {-Not essential in immune individuals since antibody-mediated clearance } \\
\text { of pRBCs was overtaken by other organs though with less efficiency } \\
\text { (reviewed in }[15] \text { ). }\end{array}$ & $\begin{array}{l}\text {-Role of the spleen in parasite killing and immune response during crisis } \\
\text { in } P \text {. chabaudi adami-mouse and } P \text {. berghei-rat infected models [23,109] } \\
\text {-Influence of host genotype in the splenic response to infection: removal of } \\
\text { the spleen in P. yoelii 17X-BalB/c mice aggravated non-lethal malaria and } \\
\text { ameliorated lethal malaria [21], while it had no effect in DBA/2 mice [19], } \\
\text { in which alternative mechanisms, such as pRBC phagocytosis in the liver } \\
\text { and/or bone marrow hematopoiesis, may supply its function. }\end{array}$ \\
\hline
\end{tabular}
acute attacks [16].

-Reduced risk of severe complications, such as cerebral malaria, could be related to retention of $P$. falciparum ring forms in the spleen that reduces the parasite biomass that sequesters in vital organs [108].

Pathogenic features related to the presence of the spleen

Spleen effect on parasite variant genes

Sequestration and cytoadherence of pRBCs in the spleen

Structural remodeling and vascular changes
-Cordal expansion and sequestration of altered RBCs [42]

-Mechanical retention of the less deformable subset of ring forms of $P$. falciparum in an ex vivo model of the spleen [108]

-High prevalence of $P$. vivax-infected reticulocytes in the ruptured spleen of an untreated $P$. vivax patient during active infection [50]. -P. vivax VIR-mediated cytoadherence to ICAM-1 and spleen cells in vitro under flow conditions [120]

-P. falciparum and $P$. vivax parasites were reported to induce splenic infarction and capsule distension based on CT images [88-90]

-Agglutination of parasitized cells in the splenic vasculature in cases leading to infarction or spontaneous spleen rupture. Vascular changes occurring during gradual progressive enlargement of the spleen [1].

-White pulp expansion and a diffuse hypercellularity in the splenic red pulp, reported from morphological studies of post-mortem or spleen-rupture cases.

-In P. falciparum and acute malaria, reactive white pulp nodules were red pulp expansion and abundant hemozoin accumulation were common, with less marked changes in the white pulp [3].

-Immunohistochemical studies of spleen sections from patients dying from severe $P$. falciparum malaria revealed disorganization characterized by MZ B cell loss, and eventually, MZ loss [49]. -Presence of large numbers of mitotic plasmablasts in peri-vascular spaces of an untreated ruptured spleen from a $P$. vivax patient [50] -The existence of barrier cells in the human spleen remains controversial in malaria even though their presence in the human spleen in other pathologies has been substantiated [1].

-Littoral cells may be key mediators of pathogen clearance and cellular filtration, with unique markers enabling them to perform surveillance of circulating cells, and discriminating between permitting entry back into circulation or blocking passage

-Red pulp macrophages uptake circulating and opsonized pRBCs [22,125] -An ex vivo human spleen model shows that more than $90 \%$ of artesunate pretreated-iRBCs were retained and processed in the red pulp [93]

-In P. falciparum, removal of crisis forms or drug-treated pRBCs is achieved

through "pitting" [18]. predominant, some displaying fibrinoid necrosis. In chronic malaria,
-Spleen-derived reticulocytes provide a pool for parasitation in P. yoelii/DBA/2 mouse model [19]

-Thrombocytopenia has been related to the presence of a spleen in P. chabaudi infected mice [111]..

-Priming of CD4 and CD8 T cells in the spleen contributed to development of $P$. berghei experimental cerebral malaria, which was reversed by splenectomy or by T cell depletion [112].

-Absence of variant surface antigens and lack of sequestration of parasites after splenectomy in P. knowlesi-, P. fragile- and P. falciparum-infected monkey models [114-118]; and in P. chabaudi chabaudi AS-CBA/Ca mice [119]

-Intravital imaging studies of the dynamic passage of $P$. yoelii 17X through the spleen demonstrated accumulation and active cytoadherence of infected reticulocytes to a spleen-blood barrier of fibroblastic origin [52] -P. berghei mutants expressing luciferase under the control of the ama1 promoter have been used to determine the distribution of sequestered schizonts in different organs including the spleen [13]

-The red pulp expands, and in mice is the site of significant hematopoiesis [121-123]

-Marginal zones are transiently lost [124], and T and B cell zones can become indistinct with extrafollicular development of plasma cells [123]

-Non-lethal $P$. yoelii infections induced a general expansion of white and red pulps, and an increase in the number of reticular and plasma cells [46]. Conversely, lethal $P$. yoelii caused widespread degeneration of reticular cells, and overcrowding of the reticular meshwork with macrophages, some of which showed intracellular or pericellular lysis [47].

-In non-lethal malaria infection of BALB/c mice with the reticulocyte-preferring $P$. yoelii $17 \mathrm{X}$, the "open" circulation of the spleen is suddenly and temporarily changed to a "closed" circulation, through the appearance of barrier cells [46]. Such cells putatively contain receptors for the specific cytoadherence of $P$. yoelii 17X infected reticulocytes allowing macrophage-clearance escape and establishment of chronic infections [52] -Identification of a fibroblastic barrier to which parasites sequestered and its changes throughout the course of infection with P. yoelii [52]

-Red pulp macrophages involved in removal of Plasmodium infected RBC [23 -Inflammatory monocytes, which migrate into the spleen during an acute $P$. chabaudi infection phagocytose iRBC in the spleen and contribute to the control of acute parasitemia [126,127] -Adoptive transfer of splenocytes to splenectomized mice confers protection to $P$. chabaudi infection $[20,128]$ 
Table 1 (continued)

\begin{tabular}{|c|c|c|}
\hline & Human & Animal models \\
\hline \multirow[t]{7}{*}{ Immune response } & -Preferential phagocytosis of immature parasite forms [43]. & $\begin{array}{l}\text {-Two-photon microscopy has reported T-DC synapses in the marginal zone } \\
\text { and red pulp of the spleen }[72,73] \text {, respectively. }\end{array}$ \\
\hline & $\begin{array}{l}\text {-Splenic dendritic cells are increased in malaria and there is a reduction } \\
\text { of B lymphocytes and macrophages in the splenic cords [49] }\end{array}$ & $\begin{array}{l}\text {-Both populations of classical DC can take up parasite material, process } \\
\text { and present Plasmodium peptides to CD4 T cells }[129,130] \text { but with } \\
\text { different kinetics. }\end{array}$ \\
\hline & $\begin{array}{l}\text {-In P. vivax, a large plasmablastic proliferation in vascular and } \\
\text { peri-vascular spaces, as well as significant increase in B-cells and } \\
\text { plasma cells, confirmed a robust humoral immune response during } \\
\text { active non-treated infection [50] }\end{array}$ & $\begin{array}{l}\text {-Viable } P \text {. berghei parasites have been observed in plasmacytoid DC in vivo } \\
\text { [131]. Whether this could result in parasite destruction and antigen } \\
\text { presentation remains unknown. }\end{array}$ \\
\hline & & $\begin{array}{l}\text {-Suggestions that splenic DCs during infection are unable to activate T cells } \\
\text { effectively in vitro [132-136] }\end{array}$ \\
\hline & & $\begin{array}{l}\text {-Prominent germinal center formation and generation of a long-lived } \\
\text { memory B and CD4 T cell response as well as long-lived plasma cells and } \\
\text { protective antibodies }[137,138]\end{array}$ \\
\hline & & $\begin{array}{l}\text {-T cell recruitment to and migration within the white pulp were suggested } \\
\text { to be directed by fibroblast channels originating in the marginal zone }[70,71]\end{array}$ \\
\hline & & $\begin{array}{l}\text {-The conduit system in the white pulp [28] may be implicated in the } \\
\text { directional movement of lymphocytes via the display of specific chemokines. }\end{array}$ \\
\hline
\end{tabular}

lacking [29]. Ogembo et al. recently focused on the relevance of unique markers expressed on littoral cells, which may enable them to perform surveillance of circulating cells, and discriminating, based on their content and overall status, between permitting entry into circulation or blocking passage. FHOD1 and SIRP $\alpha$ (CD172a) were the main markers addressed in this study [29]. On one hand, the highly polarized expression of SIRP $\alpha$ hints towards a role in mediation of RBC turnover, phagocytosis, and iron regulation [31,32] via its interaction with CD47. SIRP1 $\alpha$ is believed to transduce negative intracellular signals that block phagocytosis, so that upon reduced CD47 (as is the case of senescent RBCs), signaling leading to cell destruction would ensue, while absence of such signal would enable passage into the sinus. On the other hand, the marker FHOD1, a member of the Drosophila-related formin family of actin regulator proteins, is believed to control various cellular phenomena including cytoskeletal regulation, and is believed to be related to the littoral cells' function in relation to antigens/pathogens, and cell invasion/internalization [33-35]. Other markers of interest in littoral cells include DARC, a chemokine receptor known for its relation to malaria; and CD8 $\alpha / \alpha$ among others [29]. The multi-lineage characteristics of, and the plethora of antigens expressed by littoral cells make them an attractive research target in general, and for future malaria research in particular.

\section{Ex vivo imaging of the spleen}

Over the last few decades, the transfer of imaging technology into the biology domain has improved our understanding of splenic architecture, and given clues on the immunological impact of splenic remodeling. It is expected that the rapid and continuous improvement of imaging techniques will provide better insight into the implications of host-pathogen interactions at the spleen and its role in clinical outcomes [36,37].

\subsection{Light microscopy}

Light microscopy has enabled the observation of phenomena such as congestion of the spleen with parasitized RBCs, accumulation of hemozoin and hemosiderin in splenic cords, and differential white pulp and red pulp remodeling upon infection with malarial parasites. The study of changes to splenic tissue and parasite accumulation, has been greatly aided by techniques including hematoxylin and eosin staining, and Giemsa staining visualized under polarized light. The former technique has led to characterization of changes in splenic compartments, most importantly the red pulp, periarteriolar lymphoid sheath, and marginal zones of infected hosts. The latter technique has enabled detection of, for instance, parasite localization in splenic compartments and their quantification due to the refringent properties of hemozoin. Additionally, immunohistochemical (IHC) histology has enabled the study of specific splenic lymphocyte populations throughout the course of infection. Cell populations whose nature and timing have been partially studied in fixed samples from humans and mice include neutrophils, red pulp macrophages, T cells (including CD4 +, CD8 + and regulatory T cells), B cells, marginal zone and metalophillic macrophages, marginal zone B cells, and splenic dendritic cells, among others [38].

Aside from lymphocyte characterization, light microscopy has also enabled the observation of agglutination of parasitized cells in the splenic vasculature in cases leading to infarction or spontaneous spleen rupture, as well as vascular changes occurring during gradual progressive enlargement of the spleen [1]. The recent advent of other imaging techniques has enabled increased resolution, higher tissue penetration, and in vivo dynamic imaging. Nevertheless, the light microscope remains a valuable diagnostic tool for splenic pathology.

\subsection{Electron microscopy}

Electron microscopy (EM) observations of the normal spleen were published almost four decades ago. These include the complex vascular architecture and microcirculation in the spleen, and its implications for pathology [39]. They also include analyses of the ultrastructure of the red pulp in the human spleen, including the close relationship between splenic cords, splenic sinuses and macrophages, and their relevance for malaria $[5,40]$. Furthermore, transmission (TEM) studies enabled the recognition that reticular cells form a spongework which constitutes the filtration mechanism of the spleen, and that this filtration meshwork differs in different parts of the spleen [41]. Additionally, TEM and scanning (SEM) studies have provided insight of erythrocyte pliancy - deformability and elasticity - upon their transit through the spleen [42]. These include observations on the alterations in the cellular configuration of RBCs which leads to cordal expansion and sequestration.

In the context of malaria, studies using electron microscopy have described events such as the interaction of parasitized erythrocytes with heterogeneous populations of phagocytic cells, whereby preferential phagocytosis of immature forms of parasites was observed [43]. Other observations include phenomena such as splenic trapping, pitting $[15,44]$, destruction of infected and uninfected erythrocytes, adherence to splenic walls, differential association of phagosomes, and rosetting $[43,45]$. 
One of the major contributions of EM to our understanding of Plasmodium interactions in the spleen in rodent models came from Leon Weiss and collaborators. In 1986, Weiss et al. published the first detailed description of the architectural changes induced in the spleens of mice infected with lethal and non-lethal strains of $P$. yoelii. Non-lethal $P$. yoelii infections induced a general expansion of white and red pulps, and an increase in the number of reticular and plasma cells [46]. On the other hand, the lethal form of $P$. yoelii was mostly characterized by widespread degeneration of reticular cells, and overcrowding of the reticular meshwork with macrophages, which showed intracellular or pericellular lysis [47]. In this model, failure to control parasitemia led to failure to relief anemia, and to continued increase of parasitemia up to $60-85 \%$ and death. These observations are consistent with observations in human spleens. In P. falciparum and acute malaria, reactive white pulp nodules were shown to be predominant, and in some cases displayed fibrinoid necrosis. In chronic malaria, red pulp expansion and abundant hemozoin accumulation were common, with less marked changes in the white pulp [3].

\subsection{Fluorescence microscopy}

Fluorescence microscopy has enabled the study of biological specimens on a structural level, and is dependent on sample fluorescence either through the use of fluorescent stains, immunofluorescence, or genetic modification to introduce a fluorescent protein reporter [48]. Major advances in this field include the introduction of bright-field and dark-field microscopy, the advent of fluorescent dyes, and the introduction of labeled antibodies, as well as the surge of epifluorescence, confocal, and super-resolution microscopies which has enabled the study of specific splenic population changes in lethal and in non-lethal malaria in rodents and humans.

Urban et al. published one of the first immunohistochemical studies of spleen sections from patients dying from severe $P$. falciparum malaria [49]. By labeling with various leukocyte markers, including neutrophils, myeloid dendritic cells, T cells, and B cells, they were able to show differential patterns of splenic architectural disorganization in fatal malaria cases, mainly characterized by MZ B cell loss, and eventually, marginal zone loss. More recently, the first confocal fluorescence and IHC study of an untreated ruptured spleen from a $P$. vivax patient demonstrated the presence of large numbers of mitotic plasmablasts in peri-vascular spaces as well as a high prevalence of $P$. vivax-infected reticulocytes outside macrophages [50].

Detailed information on structural and functional changes in spleen cell populations in rodent models infected with Plasmodium strains of different levels of lethality has also been obtained through fluorescence imaging. Krucken et al. showed malaria-inducible spleen-inherent closing mechanisms controlling the uptake of parasitized and nonparasitized RBCs and explored the potential role of TNF/TNFR1 signaling in regulation of splenic closure, thereby challenging the idea of complex mechanisms of sequestration developed by the parasite to avoid passage through the spleen [51]. Yet, more recent work on lethal and non-lethal GFP-transgenic P. yoelii strains used immunofluorescence to confirm the identification of a fibroblastic barrier to which parasites sequestered and its changes throughout the course of infection with P. yoelii [52]. Additional to changes in splenic structure, fluorescence microscopy has enabled the study of various phenomena including pitting and spherocyte formation [53], red blood cell deformability and spleen-filtering functions [15,54-56].

\section{In vivo imaging}

The possibility to observe immune cells and infectious agents in realtime during their dynamic passage and interactions in living tissues is generating new and unsuspected insights into host-pathogen interactions, including malaria [57-59]. Noticeably, imaging of the spleen in malarial infections is challenging our present views on the role of this organ in infections and is opening new avenues for our understanding of immune cells and the mechanisms elicited by iRBC in their passage through this lymphoid organ.

Diverse imaging modes have been engineered based on energymatter interactions. Their suitability to image live small animal models depends on their specific features and the spatiotemporal resolution achieved [60,61]. On one hand, intravital microscopy techniques (IVM) have been extensively used to image dynamic molecular and cellular events within tissues, achieving high spatiotemporal resolution $(\mu \mathrm{m} / \mathrm{s})$. As it is based on light interactions, it usually requires surgical exposure of the organ of study and imaging is restricted to short depths beyond the exposed surface. On the other hand, non-invasive imaging techniques, such as magnetic resonance imaging (MRI), radiotracer modalities (scintigraphy, positron emission tomography (PET) and single-photon emission computed tomography (SPECT)), X-ray computed tomography $(\mathrm{CT})$, ultrasound and bioluminiscence systems, permit whole body imaging with repeated observations of the same subject over longitudinal studies. Though they can penetrate deep into the tis-

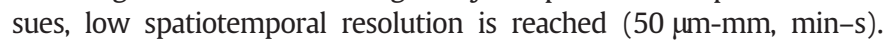
Some applications of these techniques include biodistribution analyses, metabolite tracking, cell migration and imaging of tissue architecture and vascularity.

\subsection{Intravital imaging}

Intravital imaging using two-photon laser scanning microscopy was pioneered in 1990 and has since revolutionized our understanding of biological systems [62]. In malaria, implementation of intravital imaging has provided knowledge of the mechanisms of parasite invasion, dissemination and tissue distribution at different stages of the life cycle, including the mosquito and mammalian hosts [52,57,63-67]. Plasmodium transgenic lines for GFP or RFP derivatives, like tdTomato and mCherry, have been created to unveil dynamics of parasite behavior and to image parasite-host cell interactions in GFP-expressing cell subsets of transgenic mouse strains [68]. With the implementation of intravital microscopy to experimental models of malaria, the journey of malaria parasites to the blood is revealed much more complex than originally thought $[66,69]$. Moreover, in vivo imaging of parasite-host interactions in the context of immunity and disease paves the way for the understanding of malaria pathogenesis.

The spleen is a particularly difficult organ for imaging as it accounts for a three-dimensional branched vasculature, containing both closed/ rapid and open/slow circulations, and a compartmentalized parenchyma (red pulp, white pulp and marginal zone) enclosed within a dense capsule [1]. Implementation of intravital imaging of the spleen was first accomplished by Grayson et al. to assess $\mathrm{T}$ cell recruitment in the white pulp [70], in which migration was later suggested to be directed by fibroblast channels originating in the marginal zone [70,71]. Other studies using two-photon microscopy have reported T-DC synapses in the marginal zone and red pulp of the spleen [72,73], respectively. As well, clustering of $\mathrm{T}$ cells in the white pulp was visualized ex vivo in Listeria experimental infections [74] and another study reported clusters of monocytes in the cords of subcapsular red pulp that functioned as storage for their rapid deployment to regulate inflammation [75].

The implementation of intravital microscopy of the spleen in malaria used the rodent Balb/c-P. yoelii 17X-GFP model [52] and opened the possibility of investigating the dynamic passage of parasites through this organ. In this pioneering study, the dynamics of parasite-spleen interplay were assessed through intravital microscopy to the spleen in Balb/c mice infected with two GFP-expressing P. yoelii strains (17XL) or (17X) infections. Parasites were imaged passing through the spleen at day 3 p.i. using laser scanning confocal microscopy and characterized off-line. As control, uninfected mice were injected with FITC-labeled RBCs. Of interest, erythrocyte reflection and intravascular dyes were used to identify the microcirculation and to measure blood flow in this organ, which is an important factor to control when studying cell 
dynamics [76]. Moreover, it allowed sufficient penetration to visualize events in the subcapsular zone, composed mainly of red pulp [75], and permitted high scanning velocities when used in resonance mode. In vivo images of the passage of the non-lethal strain showed an adhesive, rolling-circle behavior of pRBCs in real time.

\subsection{Quantitative imaging of parasite-spleen interactions}

Intravital imaging of GFP parasites in the spleen revealed differences in mobility between the two strains of parasites [52]. In order to quantify and compare pRBC mobility, specific procedures were developed to track individual particles in space and time [77], where automatic software failed to follow fast moving particles over time. Comparative analysis between P. yoelii 17XL and17X strains and between uninfected mice injected with FITC-labeled RBCs revealed significant differences in the accumulation and dynamic behaviors of parasite populations. To avoid any confounding result, parasites were imaged passing through the spleen at day 3 post-infection, when hematocrit, reticulocytemia, parasitemia and host cell invasion preference are comparable in both strains. Quantitative analysis of mobility parameters of single parasites indicated reduced velocity, lack of directionality and augmented residence time of parasites of mice infected with $17 \mathrm{X}$ strain overall suggesting adhesion to spleen cells. Of note, the parameters used to describe parasite mobility have been previously described in other studies to report lymphocyte recruitment and adhesion in vivo $[70,78]$. Thus, this methodology and parameters should be considered a new tool to the in vivo studies of adherence in malaria. Whether the adherent population in non-lethal infected mice corresponded to infected reticulocytes and the developmental stage of the parasites remains to be determined. Of interest, blood flow in this organ was calculated from the streaks resulting from moving RBCs when imaged with high line average in vessels with different diameters and over different phases of the cardiac cycle. In the future, this technology may be used to gain insight into the immunobiology and parasite-spleen cell interactions by imaging infection in transgenic mice expressing fluorescent reporter genes in different cells. Moreover, the generation of transgenic parasites expressing fluorescent markers other than GFP may be used in combination to image dual infections in this model (Fig. 1).

\subsection{Bioluminiscence}

Bioluminiscence imaging (BLI) refers to the process of visible light emission in living organisms as initially shown after cloning and expression of the first luciferase gene in bacteria [79-81]. Its power as an imaging tool lies on its non-invasiveness, easy use, deep penetration, and reduction of the number of animals required for experimentation. Bioluminiscence imaging systems allow relative quantification of luciferase activity in the whole body of live small animals, or in their dissected organs, by detection of the luminescent signal resulting from the enzymatic degradation of an exogenous substrate [81].

Since its first application in vivo in a rodent model of Salmonella infection [82], different pathogens and cells have been genetically modified to express luciferase enzymes from bacteria, insects, and the sea pansy [83]. Plasmodium berghei transgenic parasites expressing the firefly luciferase reporter protein at different developmental stages [84] have been created to study the distribution and sequestration patterns of infected red blood cells (pRBCs) in rodent host tissues [63]. Moreover, the development of Plasmodium preerythrocytic stages in the liver has been studied in detail by means of intravital microscopy using transgenic parasites that express fluorescent reporter proteins [66]. The possibility to visualize individual liver schizonts from bioluminiscence signals [85] may offer the opportunity to further analyze the process of merosome formation, release and migration to the lungs. To evaluate the use of bioluminiscence systems in investigating both preerythrocytic and erythrocytic stages of the parasite for vaccine and drug discovery, Mwakingwe et al. performed imaging of mice infected with sporozoites of a P. yoelii YM-Luciferase transgenic line [86].

Plasmodium parasites have been engineered to enable the simultaneous expression of fluorescent and luciferase protein reporters [85], which makes them jump to the micron scale for further studies of the role of the spleen in infections. To illustrate its usage in imaging the spleen, Franke-Fayard and collaborators have recently used $P$. berghei mutants expressing luciferase under the control of the strong ama1 promoter to determine the distribution of sequestered schizonts in different organs including the spleen [13]. Their results have elegantly shown that in this model of sequestration analogous to $P$. falciparum, nonsequestering parasites have reduced growth indicating the importance of spleen clearance in this model (Fig. 2). More recently, we have used $P$. yoelii expressing GFP/luciferase to study the distribution of the parasite after intraperitoneal injection of mice with infected RBCs. Real-time monitoring of infection revealed the accumulation of parasite on day 3 p.i. mainly in the spleen and also in the lungs. As the infection progresses, the accumulation of parasites in the lung was larger and appears also in other organs (heart, kidneys, liver) (not shown). Bioluminescence is rapid and sensitive and requires little manipulation, allowing real-time monitoring of individual animals. It is thus foreseen that this technology will rapidly advance our knowledge of the role of the spleen in different models.

\subsection{Magnetic resonance imaging}

Magnetic resonance imaging offers a variety of tools to obtain functional, anatomical and molecular information with high contrast in soft tissues [60]. Implementation of microMRI to investigate changes in the murine spleen upon malaria infection has only recently been achieved [52]. Differences in splenic remodeling induced by lethal and nonlethal P. yoelii strains were assessed on abdominal T2-weighted scans. Quantitative measures obtained on red and white pulp areas showed prolonged T2 relaxation times in the white pulp of infected mice, likely revealing edema, hyperplasia and/or proliferation of the lymphoid compartment. Moreover, T2 variances were accentuated in spleens of mice infected with non-lethal strain, in which signal heterogeneity has been attributed elsewhere to fibrosis, necrosis and hemorrhage, thus reinforcing evidence of structural reorganization in the malarial spleen [52] (Fig. 3).

Though we are far from studying the dynamics of infection in this organ in humans, the advent of powerful non invasive imaging techniques and the development of specific probes offer promising development for studying infection at adequate spatiotemporal resolution, not restricted to endpoint or snapshots of histopathological studies.

\section{The human spleen}

With the advent of non-invasive imaging techniques in the medical field, a consistent bridge is being built that helps to extrapolate research from animal models to human disease.

\subsection{Computed tomography: findings in human malarial spleen}

During malaria infection, changes in splenic architecture and cellularity result in tissue enlargement, infarction and/or ultimately rupture. Arterial phase CT scans revealed an abnormal enhancement of malarial splenic parenchyma that progressively regressed to a normal pattern where differences in blood flow between red and white pulp become apparent after antimalarial treatment [87]. Both P. falciparum and $P$. vivax malaria cases have been reported to induce splenic infarction based on $\mathrm{CT}$ images showing hypodense heterogeneous multifocal areas $[88,89]$. This pathology seems to be increasing among nonimmune travelers despite antimalarial prophylaxis and may eventually trigger splenic rupture, which is a life-threatening complication in malaria disease. Analysis of 55 cases of malarial splenic rupture revealed 
A Red pulp microcirculation

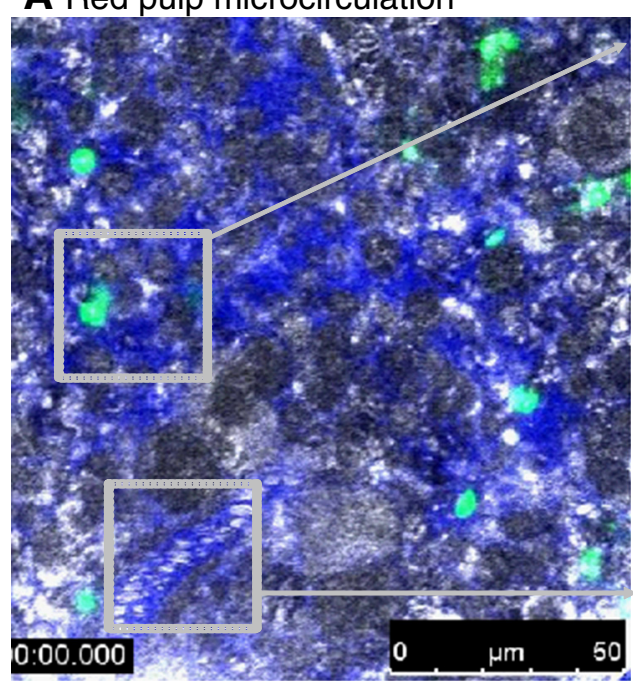

B Manual tracking of individual particles

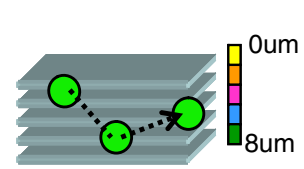

t0-t1

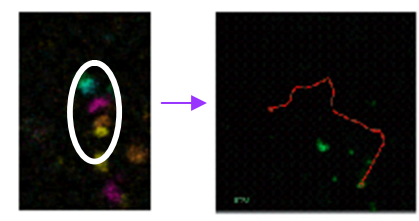

D

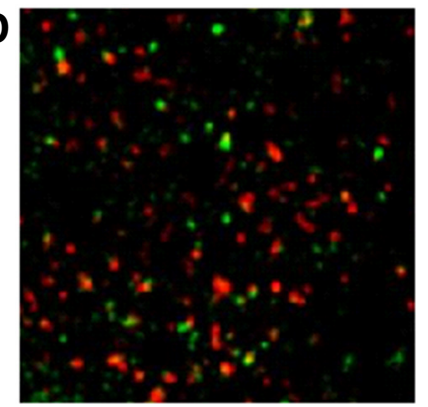

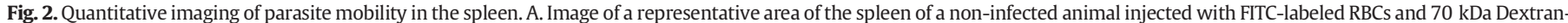

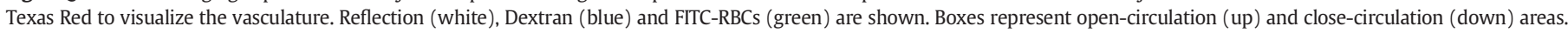

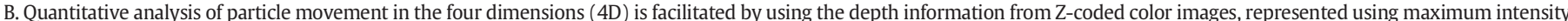

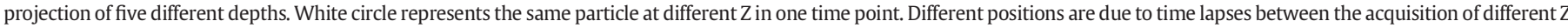

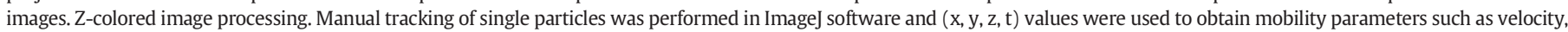

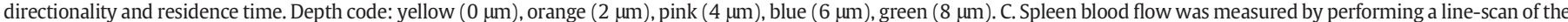

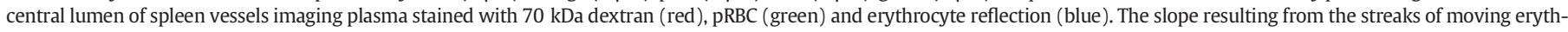

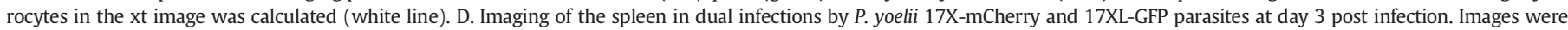
obtained in a Leica TCS-SP5 confocal microscope. (For interpretation of the references to color in this figure legend, the reader is referred to the web version of this article.)

several features associated with this lesion, namely splenic enlargement and capsule distension, regardless of the causative Plasmodium species [15]. Of note, splenomegaly and risk of splenic rupture were still exacerbated in P. vivax malaria and non-immune patients [90]. Though splenectomy has long been the treatment of choice for this pathology, new interventions are committed to conservative management that takes advantage of CT, ultrasonography and/or MR scans for diagnosis and daily monitoring of tissue recovery [91].

\subsection{Ultrasonography}

Ultrasound imaging has higher spatial and temporal resolution than CT and MR and allows for the dynamic detection of tissue flow of both macro and microvasculatures [92]. The circulatory pattern of the human spleen has been recently investigated in vivo by means of contrast-enhanced ultrasonography using microbubbles [15]. In this study, the authors showed a dual microcirculatory organization with
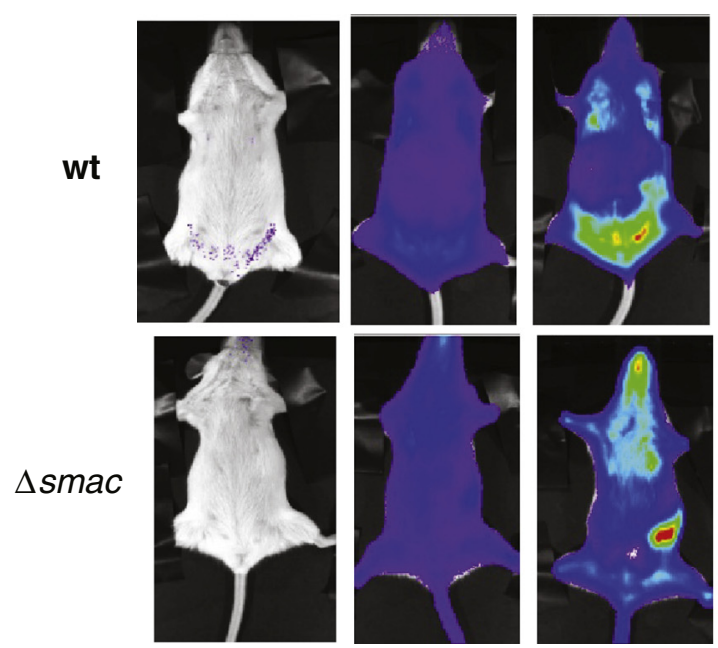

$15 \mathrm{hpi}$

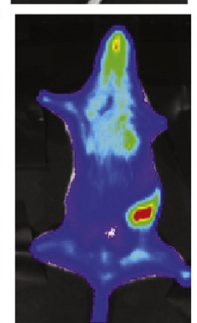

22 hpi
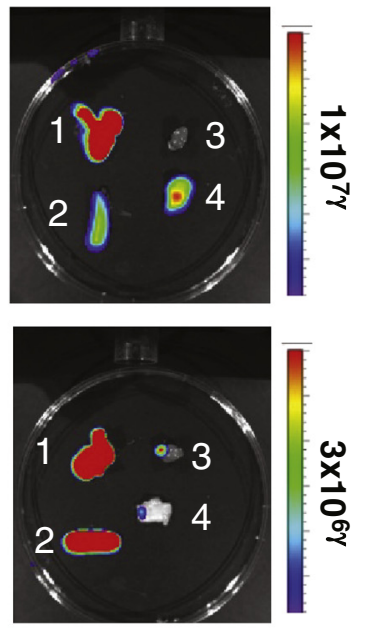

22 hpi

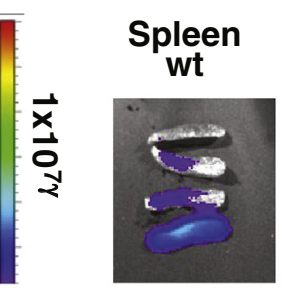

Spleen $\Delta s m a c$

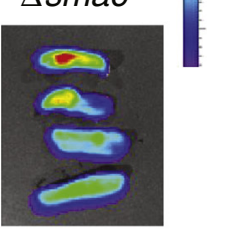

22 hpi

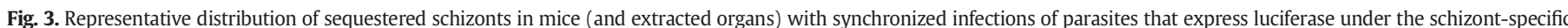

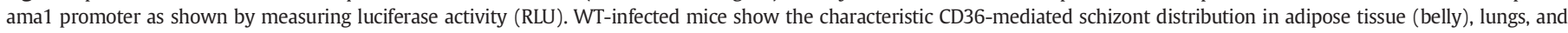

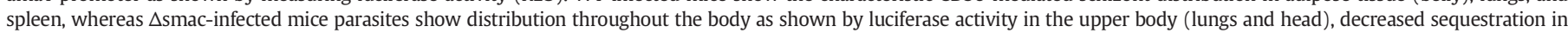
adipose tissue, and increased accumulation in the spleen (1, lungs; 2 , spleen; 3 , heart; 4 , belly fat tissue). Original figure published in [13]. 
approximately $10 \%$ of the blood input flowing through the slow compartment. In addition, the development of a system for ex vivo perfusion of intact human spleen enabled the study of $P$. falciparum-RBC clearance in an intact spleen, independent from parasite-priming and serum factors, where ring-iRBC retained in the slow compartment of the red pulp [93].

The portability and affordability of ultrasound equipment have permitted its application in endemic areas to study malaria-related alterations of microvasculature [94] and to monitor spleen size as a sign for asymptomatic malaria and chronicity, though it cannot be used as a first line diagnostic technique [95].

\subsection{Other findings from radionuclide imaging of the spleen}

Using scintillographic imaging, increased uptake of Tc-99m sulfur colloid was detected in the spleen, liver and lungs of malaria patients; with $P$. falciparum and $P$. vivax having severe cases exacerbating pulmonary clearance and splenic clearance, respectively. Interestingly, Karanikas et al. implemented this technology to assess the kinetics and biodistribution of autologous ${ }^{111}$ In-labeled platelets in malaria patients with thrombocytopenia. Scintigraphic imaging indicated a diffuse pattern of sequestration, thus discarding the spleen and liver as major sites for platelet destruction and rather pointing to reduced platelet lifespan as the cause for thrombocytopenia [96].

\section{Future perspectives}

\subsection{Novel imaging technologies}

While major advances in our knowledge of spleen structure and function, and its role in malaria pathology have been achieved with the aid of imaging modalities as reviewed above, novel techniques currently unexplored, hold potential important contributions in the context of spleen-malaria interactions. They include, among others, optical projection tomography (OPT), atomic force microscopy (AFM), spinning disc microscopy, infrared microspectroscopy, 4D electron microscopy, and fluorescence microendoscopy. The potential of some of these techniques are discussed below.

Optical projection tomography (OPT) is a relatively new technique that enables 3D imaging of biological specimens ranging from 1 to $10 \mathrm{~mm}$. Its main advantages include higher resolution imaging than MRI while enabling visualization of samples larger than those used for confocal-laser microscopy imaging; and the possibility of doing transmission and fluorescence imaging studies allowing for tissue- or genespecific staining [97]. Recent work with OPT includes organogenesis and developmental studies, as well as lymph node vascular and HEV changes upon infection and inflammation [98]. Its use in spleen studies remains to be reported.

As opposed to OPT, which enables visualization at a macro-level, atomic force microscopy enables resolution in the order of fractions of a nanometer, thus allowing exploration of subcellular structures and biomolecules. This imaging technique has been used to study structures from whole cells to individual micromolecules, and their micromechanical properties. Moreover, AFM enables studying of biological specimens in a near physiological environment, and thus includes the possibility of real-time dynamic studies, and structurefunction correlations at a molecular level [99]. In the context of malaria, it has mostly been used to visualize morphological changes occurring in infected erythrocytes $[100,101]$, yet its use for host-pathogen interaction or organ-specific pathology remains unexplored.

A further imaging technique recently introduced to the field of biology, and which has gained attention due to its potential for realtime imaging, is 4D electron microscopy [102]. This technique enables nanosecond high-speed imaging while maintaining high spatial resolution, and its applications in biology include phenomena ranging from atomic motions in structures, to chemical bonding, phase transitions, and nanomechanical properties of complex systems. Its use for understanding nanometric and subcellular changes at an organ level in real time remains to be explored.

Finally, one of the main challenges ahead is to visualize deep tissue spleen structures. The recent usage of fluorescence microendoscopy to visualize deep brain areas [103], combined with constantly evolving better lasers, optics and detectors, seems a promising approach.

\subsection{D model of the human spleen}

The complex microcirculation comprising both closed and open circulation and the compartmentalization with different cells and functions limits our present 2D view of this organ. However, recent advances in bioengineering and microfluidics coupled to imaging, are paving the way to construct 3D organs-on-a-chip, including the spleen [104-106]. Although many challenges remain ahead, it is envisaged that a combination of 3D models of the human spleen, microfluidics and imaging along with clinical observations will soon give us an alternative, accurate and affordable dynamic view of the role of the spleen in normal and pathological conditions caused by malaria and other blood disorders.

\section{Concluding remarks}

The implementation of imaging into the studies of the spleen in normal and pathological conditions caused by malarial infections is rapidly changing its classical view of the "blackbox" in the abdominal cavity. In fact, ex vivo approaches were fundamental in the description of its compartments and cells; yet, these approaches are now being replaced by real-time in vivo studies in animal models allowing a comprehensive view at spatial and temporal resolution of the 3D complex structure and function of the spleen. Indeed, it is foreseen that advances in optics and fluorescence probes will soon allow cell/tissue resolution of the human spleen. Ultimately, imaging of the spleen in experimental and natural infections at this molecular dynamic level will make feasible the development of new diagnostics and the testing of the mechanisms and effectiveness of drugs and vaccines to treat the disease and to further elucidate the role of immune effector cells and mechanisms during malarial infection.

\section{Acknowledgments}

Work in the laboratory of HAP is funded by the European Community's Seventh Framework Programme (grant agreement no 242095) and by the Ministerio Español de Economia y Competitividad, Spain (SAF2012-35133).

\section{References}

[1] Bowdler AJ. The complete spleen2nd ed. . Humana Press; 2002.

[2] Engwerda CR, Beattie L, Amante FH. The importance of the spleen in malaria. Trends Parasitol 2005;21:75-80.

[3] Wilkins BS. The spleen. Br J Haematol 2002;117:265-74.

[4] Drevelengas A. The spleen in infectious disorders. JBR-BTR 2000;83:208-10.

[5] Steiniger B, Barth P. Microanatomy and function of the spleen. Adv Anat Embryol Cell Biol 2000;151(III-IX):1-101.

[6] Wei SH, Miller MJ, Cahalan MD, Parker I. Two-photon imaging in intact lymphoid tissue. Adv Exp Med Biol 2002;512:203-8.

[7] Cahalan MD, Parker I, Wei SH, Miller MJ. Two-photon tissue imaging: seeing the immune system in a fresh light. Nat Rev Immunol 2002;2:872-80.

[8] Neva FA, Sheagren JN, Shulman NR, Canfield CJ. Malaria: host-defense mechanisms and complications. Ann Intern Med 1970;73:295-306.

[9] Snow RW, Shenton FC, Lindsay SW, Greenwood BM, Bennett S, Wheeler J, et al. Sporozoite antibodies and malaria in children in a rural area of The Gambia. Ann Trop Med Parasitol 1989;83:559-68.

[10] Chaves LF, Taleo G, Kalkoa M, Kaneko A. Spleen rates in children: an old and new surveillance tool for malaria elimination initiatives in island settings. Trans $\mathrm{R}$ Soc Trop Med Hyg 2011;105:226-31.

[11] Del Portillo HA, Ferrer M, Brugat T, Martin-Jaular L, Langhorne J, Lacerda MV. The role of the spleen in malaria. Cell Microbiol 2012;14:343-55. 
[12] Buffet PA, Safeukui I, Milon G, Mercereau-Puijalon O, David PH. Retention of erythrocytes in the spleen: a double-edged process in human malaria. Curr Opin Hematol 2009;16:157-64.

[13] Fonager J, Pasini EM, Braks JA, Klop O, Ramesar J, Remarque EJ, et al. Reduced CD36dependent tissue sequestration of Plasmodium-infected erythrocytes is detrimental to malaria parasite growth in vivo. J Exp Med 2012;209:93-107.

[14] Miller LH, Baruch DI, Marsh K, Doumbo OK. The pathogenic basis of malaria. Nature 2002;415:673-9.

[15] Buffet PA, Safeukui I, Deplaine G, Brousse V, Prendki V, Thellier M, et al. The pathogenesis of Plasmodium falciparum malaria in humans: insights from splenic physiology. Blood 2011;117:381-92

[16] Bachmann A, Esser C, Petter M, Predehl S, von Kalckreuth V, Schmiedel S, et al. Absence of erythrocyte sequestration and lack of multicopy gene family expression in Plasmodium falciparum from a splenectomized malaria patient. PLoS One 2009;4: e7459.

[17] Looareesuwan S, Ho M, Wattanagoon Y, White NJ, Warrell DA, Bunnag D, et al. Dynamic alteration in splenic function during acute falciparum malaria. $\mathrm{N}$ Engl J Med 1987;317:675-9.

[18] Chotivanich K, Udomsangpetch R, Dondorp A, Williams T, Angus B, Simpson JA, et al The mechanisms of parasite clearance after antimalarial treatment of Plasmodium falciparum malaria. J Infect Dis 2000;182:629-33.

[19] Sayles PC, Cooley AJ, Wassom DL. A spleen is not necessary to resolve infections with Plasmodium yoelii. Am J Trop Med Hyg 1991;44:42-8.

[20] Yap GS, Stevenson MM. Differential requirements for an intact spleen in induction and expression of B-cell-dependent immunity to Plasmodium chabaudi AS. Infect Immun 1994:62:4219-25.

[21] Weiss L. Barrier cells in the spleen. Immunol Today 1991;12:24-9.

[22] Li JL, Li YJ. Inhibitory, opsonic and cytotoxic activities of monoclonal antibodies against asexual erythrocytic stages of Plasmodium falciparum. Parasitology 1987;95(Pt 2):229-40.

[23] Yadava A, Kumar S, Dvorak JA, Milon G, Miller LH. Trafficking of Plasmodium chabaudi adami-infected erythrocytes within the mouse spleen. Proc Natl Acad Sci U S A 1996:93:4595-9.

[24] W.B. Applied veterinary histology 3rd ed. 1993.

[25] DHaB EM. Textbook of veterinary histology 6th ed. 2006

[26] Balogh PLA. Structural evolution of the spleen in man and mouse; 2011.

[27] Steiniger B, Barth P, Hellinger A. The perifollicular and marginal zones of the human splenic white pulp: do fibroblasts guide lymphocyte immigration? Am J Pathol 2001;159:501-12.

[28] Nolte MA, Belien JA, Schadee-Eestermans I, Jansen W, Unger WW, van Rooijen N, et al. A conduit system distributes chemokines and small blood-borne molecules through the splenic white pulp. J Exp Med 2003;198:505-12.

[29] Ogembo JG, Milner Jr DA, Mansfield KG, Rodig SJ, Murphy GF, Kutok JL, et al. SIRPalpha/CD172a and FHOD1 are unique markers of littoral cells, a recently evolved major cell population of red pulp of human spleen. J Immunol 2012;188:4496-505.

[30] Buckley PJ, Dickson SA, Walker WS. Human splenic sinusoidal lining cells express antigens associated with monocytes, macrophages, endothelial cells, and T lymphocytes. J Immunol 1985;134:2310-5.

[31] van den Berg TK, van der Schoot CE. Innate immune 'self' recognition: a role for CD47-SIRPalpha interactions in hematopoietic stem cell transplantation. Trends Immunol 2008;29:203-6.

[32] Kinchen JM, Ravichandran KS. Phagocytic signaling: you can touch, but you can't eat. Curr Biol 2008;18:R521-4.

[33] Gill MB, Roecklein-Canfield J, Sage DR, Zambela-Soediono M, Longtine N, Uknis M, et al. EBV attachment stimulates FHOS/FHOD1 redistribution and co-aggregation with CD21: formin interactions with the cytoplasmic domain of human CD21. J Cell Sci 2004;117:2709-20.

[34] Gasteier JE, Schroeder S, Muranyi W, Madrid R, Benichou S, Fackler OT. FHOD1 coordinates actin filament and microtubule alignment to mediate cell elongation. Exp Cell Res 2005;306:192-202.

[35] Young KG, Copeland JW. Formins in cell signaling. Biochim Biophys Acta 1803;2010:183-90.

[36] Dzhagalov IL, Melichar HJ, Ross JO, Herzmark P, Robey EA. Two-Photon Imaging of the Immune System Unit. Curr Protoc Cytom 2012;12:12.26.1-12.26.20. http:// dx.doi.org/10.1002/0471142956.cy1226s60.

[37] Herz J, Zinselmeyer BH, McGavern DB. Two-photon imaging of microbial immunity in living tissues. Microsc Microanal 2012;18:730-41.

[38] Leisewitz AL, Rockett KA, Gumede B, Jones M, Urban B, Kwiatkowski DP. Response of the splenic dendritic cell population to malaria infection. Infect Immun 2004;72:4233-9.

[39] Burke JS, Simon GT. Electron microscopy of the spleen. I. Anatomy and microcirculation. Am J Pathol 1970;58:127-55.

[40] Burke JS, Simon GT. Electron microscopy of the spleen. II. Phagocytosis of colloidal carbon. Am J Pathol 1970;58:157-81.

[41] Hirasawa Y, Tokuhiro H. Electron microscopic studies on the normal human spleen: especially on the red pulp and the reticulo-endothelial cells. Blood 1970;35:201-12.

[42] Bishop MB, Lansing LS. The spleen: a correlative overview of normal and pathologic anatomy. Hum Pathol 1982;13:334-42.

[43] Pongponratn E, Riganti M, Harinasuta T, Bunnag D. Electron microscopic study of phagocytosis in human spleen in falciparum malaria. Southeast Asian J Trop Med Public Health 1989;20:31-9.

[44] Schnitzer B, Sodeman T, Mead ML, Contacos PG. Pitting function of the spleen in malaria: ultrastructural observations. Science 1972;177:175-7.

[45] Pongponratn E, Riganti M, Bunnag D, Harinasuta T. Spleen in falciparum malaria: ultrastructural study. Southeast Asian J Trop Med Public Health 1987; 18:491-501.
[46] Weiss L, Geduldig U, Weidanz W. Mechanisms of splenic control of murine malaria: reticular cell activation and the development of a blood-spleen barrier. Am J Anat 1986;176:251-85.

[47] Weiss L, Johnson J, Weidanz W. Mechanisms of splenic control of murine malaria: tissue culture studies of the erythropoietic interplay of spleen, bone marrow, and blood in lethal (strain 17XL) Plasmodium yoelii malaria in BALB/c mice. Am J Trop Med Hyg 1989;41:135-43.

[48] Rost FWD. Fluorescence. Microscopy; 1995.

[49] Urban BC, Hien TT, Day NP, Phu NH, Roberts R, Pongponratn E, et al. Fatal Plasmodium falciparum malaria causes specific patterns of splenic architectural disorganization. Infect Immun 2005;73:1986-94.

[50] Machado Siqueira A, Lopes Magalhaes BM, Cardoso Melo G, Ferrer M, Castillo P, Martin-Jaular L, et al. Spleen rupture in a case of untreated Plasmodium vivax infection. PLoS Negl Trop Dis 2012;6:e1934.

[51] Krucken J, Mehnert LI, Dkhil MA, El-Khadragy M, Benten WP, Mossmann H, et al. Massive destruction of malaria-parasitized red blood cells despite spleen closure. Infect Immun 2005;73:6390-8.

[52] Martin-Jaular L, Ferrer M, Calvo M, Rosanas-Urgell A, Kalko S, Graewe S, et al Strain-specific spleen remodelling in Plasmodium yoelii infections in Balb/c mice facilitates adherence and spleen macrophage-clearance escape. Cell Microbiol 2011;13:109-22.

[53] Anyona SB, Schrier SL, Gichuki CW, Waitumbi JN. Pitting of malaria parasites and spherocyte formation. Malar J 2006;5:64.

[54] Antia M, Herricks T, Rathod PK. Microfluidic modeling of cell-cell interactions in malaria pathogenesis. PLoS Pathog 2007;3:e99.

[55] Herricks T, Seydel KB, Turner G, Molyneux M, Heyderman R, Taylor T, et al. A microfluidic system to study cytoadhesion of Plasmodium falciparum infected erythrocytes to primary brain microvascular endothelial cells. Lab Chip 2011:11:2994-3000.

[56] Shelby JP, White J, Ganesan K, Rathod PK, Chiu DT. A microfluidic model for singlecell capillary obstruction by Plasmodium falciparum-infected erythrocytes. Proc Nat Acad Sci U S A 2003;100:14618-22.

[57] Amino R, Menard R, Frischknecht F. In vivo imaging of malaria parasites-recent advances and future directions. Curr Opin Microbiol 2005;8:407-14.

[58] Germain RN, Robey EA, Cahalan MD. A decade of imaging cellular motility and interaction dynamics in the immune system. Science 2012;336:1676-81.

[59] Heussler V, Doerig C. In vivo imaging enters parasitology. Trends Parasitol 2006;22:192-5 [discussion 5-6].

[60] Weissleder R. Scaling down imaging: molecular mapping of cancer in mice. Nat Rev Cancer 2002;2:11-8.

[61] Kherlopian AR, Song T, Duan Q, Neimark MA, Po MJ, Gohagan JK, et al. A review of imaging techniques for systems biology. BMC Syst Biol 2008;2:74.

[62] Denk W, Strickler JH, Webb WW. Two-photon laser scanning fluorescence microscopy. Science 1990;248:73-6.

[63] Franke-Fayard B, Waters AP, Janse CJ. Real-time in vivo imaging of transgenic bioluminescent blood stages of rodent malaria parasites in mice. Nat Protoc 2006;1:476-85.

[64] Frevert U, Nardin E. Arrest in the liver-a genetically defined malaria vaccine? N Engl J Med 2005;352:1600-2.

[65] Frischknecht F, Baldacci P, Martin B, Zimmer C, Thiberge S, Olivo-Marin JC, et al. Imaging movement of malaria parasites during transmission by Anopheles mosquitoes. Cell Microbiol 2004;6:687-94.

[66] Sturm A, Amino R, van de Sand C, Regen T, Retzlaff S, Rennenberg A, et al. Manipulation of host hepatocytes by the malaria parasite for delivery into liver sinusoids. Science 2006;313:1287-90.

[67] Nacer A, Movila A, Baer K, Mikolajczak SA, Kappe SH, Frevert U. Neuroimmunological blood brain barrier opening in experimental cerebral malaria. PLoS Pathog 2012;8: e1002982.

[68] Graewe S, Retzlaff S, Struck N, Janse CJ, Heussler VT. Going live: a comparative analysis of the suitability of the RFP derivatives RedStar, mCherry and tdTomato for intravital and in vitro live imaging of Plasmodium parasites. Biotechnol J 2009;4:895-902.

[69] Amino R, Thiberge S, Blazquez S, Baldacci P, Renaud O, Shorte S, et al. Imaging malaria sporozoites in the dermis of the mammalian host. Nat Protoc 2007:2:1705-12.

[70] Grayson MH, Hotchkiss RS, Karl IE, Holtzman MJ, Chaplin DD. Intravital microscopy comparing $\mathrm{T}$ lymphocyte trafficking to the spleen and the mesenteric lymph node. Am J Physiol Heart Circ Physiol 2003;284:H2213-26.

[71] Bajenoff M, Narni-Mancinelli E, Brau F, Lauvau G. Visualizing early splenic memory CD8 $+\mathrm{T}$ cells reactivation against intracellular bacteria in the mouse. PLoS One 2010;5:e11524.

[72] Mittelbrunn M, Martinez del Hoyo G, Lopez-Bravo M, Martin-Cofreces NB, Schole A, Hugues $S$, et al. Imaging of plasmacytoid dendritic cell interactions with T cells. Blood 2009;113:75-84

[73] Morelli AE, Larregina AT, Shufesky WJ, Zahorchak AF, Logar AJ, Papworth GD, et al Internalization of circulating apoptotic cells by splenic marginal zone dendritic cells: dependence on complement receptors and effect on cytokine production. Blood 2003;101:611-20.

[74] Aoshi T, Zinselmeyer BH, Konjufca V, Lynch JN, Zhang X, Koide Y, et al. Bacteria entry to the splenic white pulp initiates antigen presentation to CD8 $+\mathrm{T}$ cells. Immunity 2008;29:476-86

[75] Swirski FK, Nahrendorf M, Etzrodt M, Wildgruber M, Cortez-Retamozo V, Panizzi P, et al. Identification of splenic reservoir monocytes and their deployment to inflammatory sites. Science 2009;325:612-6.

[76] Rogausch H, Zwingmann D, Trudewind M, del Rey A, Voigt KH, Besedovsky H. Loca and systemic autonomic nervous effects on cell migration to the spleen. J Appl Physiol 2003;94:469-75. 
[77] Ferrer M, Martin-Jaular L, Calvo M, Del Portillo HA. Intravital microscopy of the spleen: quantitative analysis of parasite mobility and blood flow. J Vis Exp 2012;59:e3609. http://dx.doi.org/10.3791/3609.

[78] Khandoga AG, Khandoga A, Reichel CA, Bihari P, Rehberg M, Krombach F. In vivo imaging and quantitative analysis of leukocyte directional migration and polarization in inflamed tissue. PLoS One 2009;4:e4693.

[79] de Wet JR, Wood KV, Helinski DR, DeLuca M. Cloning of firefly luciferase cDNA and the expression of active luciferase in Escherichia coli. Proc Natl Acad Sci U S A 1985;82:7870-3.

[80] Sadikot RT, Blackwell TS. Bioluminescence imaging. Proc Am Thorac Soc 2005;2(537-40):11-2.

[81] Sadikot RT, Blackwell TS. Bioluminescence: imaging modality for in vitro and in vivo gene expression. Methods Mol Biol 2008;477:383-94.

[82] Contag CH, Contag PR, Mullins JI, Spilman SD, Stevenson DK, Benaron DA. Photonic detection of bacterial pathogens in living hosts. Mol Microbiol 1995;18:593-603.

[83] Hastings JW. Chemistries and colors of bioluminescent reactions: a review. Gene 1996;173:5-11

[84] de Koning-Ward TF, Speranca MA, Waters AP, Janse CJ. Analysis of stage specificity of promoters in Plasmodium berghei using luciferase as a reporter. Mol Biochem Parasitol 1999;100:141-6.

[85] Ploemen IH, Prudencio M, Douradinha BG, Ramesar J, Fonager J, van Gemert GJ, et al. Visualisation and quantitative analysis of the rodent malaria liver stage by real time imaging. PLoS One 2009;4:e7881.

[86] Mwakingwe A, Ting LM, Hochman S, Chen J, Sinnis P, Kim K. Noninvasive real-time monitoring of liver-stage development of bioluminescent Plasmodium parasites. J Infect Dis 2009;200:1470-8.

[87] Karakas HM, Tuncbilek N, Okten OO. Splenic abnormalities: an overview on sectional images. Diagn Interv Radiol 2005;11:152-8

[88] Bonnard P, Guiard-Schmid JB, Develoux M, Rozenbaum W, Pialoux G. Splenic infarction during acute malaria. Trans R Soc Trop Med Hyg 2005;99:82-6.

[89] Kim A, Park YK, Lee JS, Chung MH, Kim ES. A case of symptomatic splenic infarction in vivax malaria. Korean J Parasitol 2007:45:55-8.

[90] Imbert P, Rapp C, Buffet PA. Pathological rupture of the spleen in malaria: analysis of 55 cases (1958-2008). Travel Med Infect Dis 2009;7:147-59.

[91] Choudhury J, Uttam KG, Mukhopadhyay M. Spontaneous rupture of malarial spleen. Indian Pediatr 2008;45:327-8.

[92] Cosgrove D. Ultrasound contrast agents: an overview. Eur J Radiol 2006;60:324-30

[93] Buffet PA, Milon G, Brousse V, Correas JM, Dousset B, Couvelard A, et al. Ex vivo perfusion of human spleens maintains clearing and processing functions. Blood 2006; 107:3745-52.

[94] Murphy S, Cserti-Gazdewich C, Dhabangi A, Musoke C, Nabukeera-Barungi N, Price $\mathrm{D}$, et al. Ultrasound findings in Plasmodium falciparum malaria: a pilot study. Pediatr Crit Care Med 2011;12:e58-63.

[95] Richter J, de Bernardis C, Sagir A, Walter S, Savalli E, Haussinger D. Is ultrasound useful adjunct for assessing malaria patients? Parasitol Res 2004;94:349-53.

[96] Karanikas G, Zedwitz-Liebenstein K, Eidherr H, Schuetz M, Sauerman R, Dudczak R, et al. Platelet kinetics and scintigraphic imaging in thrombocytopenic malaria patients. Thromb Haemost 2004;91:553-7.

[97] Sharpe J. Optical projection tomography as a new tool for studying embryo anatomy. J Anat 2003;202:175-81.

[98] Kumar V, Chyou S, Stein JV, Lu TT. Optical projection tomography reveals dynamics of HEV growth after immunization with protein plus CFA and features shared with HEVs in acute autoinflammatory lymphadenopathy. Front Immunol 2012:3:282.

[99] Lal R, John SA. Biological applications of atomic force microscopy. Am J Physiol 1994;266:C1-C21.

[100] Li A, Mansoor AH, Tan KS, Lim CT. Observations on the internal and surface morphology of malaria infected blood cells using optical and atomic force microscopy. J Microbiol Methods 2006;66:434-9.

[101] Nagao E, Kaneko O, Dvorak JA. Plasmodium falciparum-infected erythrocytes: qualitative and quantitative analyses of parasite-induced knobs by atomic force microscopy. J Struct Biol 2000;130:34-44.

[102] Zewail AH. Four-dimensional electron microscopy. Science 2010;328:187-93.

[103] Barretto RP, Ko TH, Jung JC, Wang TJ, Capps G, Waters AC, et al. Time-lapse imaging of disease progression in deep brain areas using fluorescence microendoscopy. Nat Med 2011:17:223-8.

[104] Baker M. Tissue models: a living system on a chip. Nature 2011;471:661-5

[105] Deplaine G, Safeukui I, Jeddi F, Lacoste F, Brousse V, Perrot S, et al. The sensing of poorly deformable red blood cells by the human spleen can be mimicked in vitro. Blood 2011;117:e88-95.

[106] Herricks T, Seydel KB, Molyneux M, Taylor T, Rathod PK. Estimating physical splenic filtration of Plasmodium falciparum-infected red blood cells in malaria patients. Cell Microbiol 2012:14:1880-91.

[107] Looareesuwan S, Suntharasamai P, Webster HK, Ho M. Malaria in splenectomized patients: report of four cases and review. Clin Infect Dis 1993;16:361-6.

[108] Safeukui I, Correas JM, Brousse V, Hirt D, Deplaine G, Mule S, et al. Retention of Plasmodium falciparum ring-infected erythrocytes in the slow, open microcirculation of the human spleen. Blood 2008;112:2520-8

[109] Quinn TC, Wyler DJ. Resolution of acute malaria (Plasmodium berghei in the rat): reversibility and spleen dependence. Am J Trop Med Hyg 1980;29:1-4

[110] Skudowitz RB, Katz J, Lurie A, Levin J, Metz J. Mechanisms of thrombocytopenia in malignant tertian malaria. Br Med J 1973:2:515-8.
[111] Watier H, Verwaerde C, Landau I, Werner E, Fontaine J, Capron A, et al. T-celldependent immunity and thrombocytopenia in rats infected with Plasmodium chabaudi. Infect Immun 1992;60:136-42.

[112] Hermsen CC, Mommers E, van de Wiel T, Sauerwein RW, Eling WM. Convulsions due to increased permeability of the blood-brain barrier in experimental cerebral malaria can be prevented by splenectomy or anti-T cell treatment. J Infect Dis 1998; $178: 1225-7$.

[113] Ho M, Bannister LH, Looareesuwan S, Suntharasamai P. Cytoadherence and ultrastructure of Plasmodium falciparum-infected erythrocytes from a splenectomized patient. Infect Immun 1992;60:2225-8.

[114] Barnwell JW, Howard RJ, Miller LH. Altered expression of Plasmodium knowlesi variant antigen on the erythrocyte membrane in splenectomized rhesus monkeys. J Immunol 1982;128:224-6.

[115] Barnwell JW, Howard RJ, Miller LH. Influence of the spleen on the expression of surface antigens on parasitized erythrocytes. Ciba Found Symp 1983;94:117-36.

[116] Handunnetti SM, Mendis KN, David PH. Antigenic variation of cloned Plasmodium fragile in its natural host Macaca sinica. Sequential appearance of successive variant antigenic types. J Exp Med 1987;165:1269-83.

[117] David PH, Hommel M, Miller LH, Udeinya IJ, Oligino LD. Parasite sequestration in Plasmodium falciparum malaria: spleen and antibody modulation of cytoadherence of infected erythrocytes. Proc Natl Acad Sci U S A 1983;80:5075-9.

[118] Hommel M, David PH, Oligino LD. Surface alterations of erythrocytes in Plasmodium falciparum malaria. Antigenic variation, antigenic diversity, and the role of the spleen. J Exp Med 1983;157:1137-48.

[119] Gilks CF, Walliker D, Newbold CI. Relationships between sequestration, antigenic variation and chronic parasitism in Plasmodium chabaudi chabaudi-a rodent malaria model. Parasite Immunol 1990;12:45-64.

[120] Bernabeu M, Lopez FJ, Ferrer M, Martin-Jaular L, Razaname A, Corradin G, et al. Functional analysis of Plasmodium vivax VIR proteins reveals different subcellular localizations and cytoadherence to the ICAM-1 endothelial receptor. Cell Microbiol 2012;14(3):386-400

[121] Freeman RR, Parish CR. Spleen cell changes during fatal and self-limiting malarial infections of mice. Immunology 1978;35:479-84.

[122] Alves HJ, Weidanz W, Weiss L. The spleen in murine Plasmodium chabaudi adami malaria: stromal cells, T lymphocytes, and hematopoiesis. Am J Trop Med Hyg 1996;55:370-8.

[123] Achtman AH, Khan M, MacLennan IC, Langhorne J. Plasmodium chabaudi chabaudi infection in mice induces strong B cell responses and striking but temporary changes in splenic cell distribution. J Immunol 2003;171:317-24.

[124] Beattie L, Engwerda CR, Wykes M, Good MF. CD8 + T lymphocyte-mediated loss of marginal metallophilic macrophages following infection with Plasmodium chabaudi chabaudi AS. J Immunol 2006;177:2518-26.

[125] McGilvray ID, Serghides L, Kapus A, Rotstein OD, Kain KC. Nonopsonic monocyte/ macrophage phagocytosis of Plasmodium falciparum-parasitized erythrocytes: a role for CD36 in malarial clearance. Blood 2000;96:3231-40.

[126] Sponaas AM, Freitas do Rosario AP, Voisine C, Mastelic B, Thompson J, Koernig S, et al. Migrating monocytes recruited to the spleen play an important role in control of blood stage malaria. Blood 2009;114:5522-31.

[127] Belyaev NN, Brown DE, Diaz AI, Rae A, Jarra W, Thompson J, et al. Induction of an IL7-R + c)-Kit(hi) myelolymphoid progenitor critically dependent on IFN-gamma signaling during acute malaria. Nat Immunol 2010;11:477-85.

[128] Winkel KD, Good MF. Inability of Plasmodium vinckei-immune spleen cells to transfer protection to recipient mice exposed to vaccine 'vectors' or heterologous species of Plasmodium Parasite Immunol 1991:13:517-30.

[129] Sponaas AM, Cadman ET, Voisine C, Harrison V, Boonstra A, O'Garra A, et al. Malaria infection changes the ability of splenic dendritic cell populations to stimulate antigen-specific T cells. J Exp Med 2006;203:1427-33.

[130] Lundie RJ, Young LJ, Davey GM, Villadangos JA, Carbone FR, Heath WR, et al. Bloodstage Plasmodium berghei infection leads to short-lived parasite-associated antigen presentation by dendritic cells. Eur J Immunol 2010;40:1674-81.

[131] Wykes MN, Kay JG, Manderson A, Liu XQ, Brown DL, Richard DJ, et al. Rodent blood-stage Plasmodium survive in dendritic cells that infect naive mice. Proc Natl Acad Sci U S A 2011;108:11205-10.

[132] Luyendyk J, Olivas OR, Ginger LA, Avery AC. Antigen-presenting cell function during Plasmodium yoelii infection. Infect Immun 2002;70:2941-9.

[133] Millington OR, Di Lorenzo C, Phillips RS, Garside P, Brewer JM. Suppression of adaptive immunity to heterologous antigens during Plasmodium infection through hemozoin-induced failure of dendritic cell function. J Biol 2006;5:5

[134] Wilson NS, Behrens GM, Lundie RJ, Smith CM, Waithman J, Young L, et al. Systemic activation of dendritic cells by Toll-like receptor ligands or malaria infection impairs cross-presentation and antiviral immunity. Nat Immunol 2006;7:165-72.

[135] Ocana-Morgner C, Mota MM, Rodriguez A. Malaria blood stage suppression of liver stage immunity by dendritic cells. J Exp Med 2003;197:143-51.

[136] Ocana-Morgner C, Wong KA, Rodriguez A. Interactions between dendritic cells and CD4 + T cells during Plasmodium infection. Malar J 2008;7:88.

[137] Ndungu FM, Cadman ET, Coulcher J, Nduati E, Couper E, Macdonald DW, et al. Functional memory B cells and long-lived plasma cells are generated after a single Plasmodium chabaudi infection in mice. PLoS Pathog 2009;5: e1000690.

[138] Stephens R, Langhorne J. Effector memory Th1 CD4 T cells are maintained in a mouse model of chronic malaria. PLoS Pathog 2010;6:e1001208. 